\title{
OPTIMALISASI HASIL PRODUKSI TAHU DAN TEMPE MENGGUNAKAN METODE BRANCH AND BOUND \\ (STUDI KASUS: PABRIK TEMPE ERI JL. TERATAI NO.04 PALU SELATAN)
}

\author{
R. K. Dg. Pagiling ${ }^{1}$, A. Sahari², Rais ${ }^{3}$ \\ 1,2,3 Program Studi Matematika Jurusan Matematika FMIPA Universitas Tadulako \\ Jalan Soekarno-Hatta Km. 09 Tondo, Palu 94118, Indonesia. \\ 1rifaldi3393@gmail.com, 2agus_sh@yahoo.com, 3rais76_untad@yahoo.co.id
}

\begin{abstract}
Factory ERI is a company that produces Tofu and Tempe which is located at JI. Teratai No.04 South Palu. ERI is a kind of factory production of Tofu, Tempeh Custody, Tempeh Round and Tempe Small involving a variety of resources that consists of raw materials (soybeans, yeast tempeh and vinegar), fuel (firewood and gasoline) and labor. Companies need to plan a strategy so that all available resources within the company used or allocated appropriately and optimally so as to produce a combined output that provides maximum production yield. Problems determinant of production to maximize the company's revenue by looking at the limited resources of the company can be solved using Integer Linier Programming model. This study aims to optimization production. One effective way to resolve the integer program is to apply algorithms Branch and Bound. For reference data on average daily production, when companies use all existing resources, namely $350 \mathrm{~kg}$ of soybean, $1 \mathrm{~m}^{3}$ wood, 3 liter Petrol, 5 grams of yeast tempeh, 2 liters of vinegar and a 14 hour/person workforce, factory can produce out of Tofu $(50 \mathrm{~cm} \times 50 \mathrm{~cm})$ as many as 24 units, Tempeh Custody $(20 \mathrm{~cm} \times 40 \mathrm{~cm})$ as many as 372 units, and Tempeh Small $(9 \mathrm{~cm} \times 14 \mathrm{~cm}) 4$ units of the income earned each day is as much as Rp. 5.259.600.
\end{abstract}

Keywords : Integer Linier Programming, Linier Programming, Methods Branch and Bound, Simplex Method, Tofu and Tempeh.

\section{ABSTRAK}

Pabrik ERI merupakan perusahaan yang memproduksi Tahu dan Tempe yang berlokasi di Jl. Teratai No.04 Palu Selatan. Jenis Produksi pabrik ERI adalah Tahu, Tempe Balak, Tempe Bulat dan Tempe Kecil dengan melibatkan berbagai sumber daya yang terdiri atas bahan baku (kedelai, ragi tempe dan cuka), bahan bakar (kayu bakar dan bensin) dan tenaga kerja. Perusahaan perlu merencanakan suatu strategi agar semua sumber daya yang ada dalam perusahaan digunakan atau dialokasikan secara tepat dan optimal sehingga dapat menghasilkan kombinasi output yang memberikan hasil produksi maksimal. Permasalahan penentu hasil produksi untuk memaksimalkan pendapatan perusahaan dengan melihat keterbatasan sumber daya perusahaan tersebut dapat diselesaikan dengan menggunakan model Program Integer. Penelitian ini bertujuan untuk megoptimalisasi hasil produksi. Salah satu cara yang cukup efektif untuk menyelesaikan program integer adalah 
dengan mengaplikasikan algoritma Branch and Bound. Untuk data acuan rata-rata produksi setiap harinya, bila perusahaan menggunakan seluruh sumber daya yang ada yaitu $350 \mathrm{~kg}$ kedelai, $1 \mathrm{~m}^{3}$ kayu bakar, 3 liter Bensin, 5 gram ragi tempe, 2 liter cuka dan 14 jam/orang tenaga kerja, pabrik dapat memproduksi Tahu $(50 \mathrm{~cm} \times 50 \mathrm{~cm})$ sebanyak 24 unit, Tempe Balak $(20 \mathrm{~cm} \times 40 \mathrm{~cm})$ sebanyak 372 unit, dan Tempe Kecil $(9 \mathrm{~cm} \times 14 \mathrm{~cm})$ sebanyak 4 unit dengan penghasilan diperoleh setiap hari adalah sebanyak Rp. 5.259.600.

Kata Kunci : Metode Branch and Bound, Metode Simpleks, Program Integer, Program Linier, Tahu dan Tempe

\section{PENDAHULUAN}

\subsection{Latar Belakang}

Pabrik Tempe ERI merupakan perusahaan yang namanya diambil dari pemilik pabrik yaitu Eri. Pabrik ini memproduksi tahu dan tiga jenis tempe yaitu tempe balak, tempe bulat dan tempe kecil. Dengan melibatkan berbagai macam sumber daya yang sifatnya terbatas diantaranya bahan baku (kedelai, ragi tempe, cuka), bahan bakar (kayu bakar, bensin) dan tenaga kerja. Dengan keterbatasan ini perusahaan perlu merencanakan suatu strategi agar semua sumber daya yang ada dalam perusahaan digunakan atau dialokasikan secara tepat dan optimal sehingga dapat menghasilkan kombinasi output yang memberikan hasil produksi maksimal. Permasalahan penentu hasil produksi untuk memaksimalkan pendapatan perusahaan dengan melihat keterbatasan sumber daya dapat diselesaikan dengan menggunakan model program linier.

Program linier adalah suatu teknik penyelesaian optimal atas suatu problem keputusan dengan cara menentukan terlebih dahulu fungsi tujuan (memaksimumkan atau meminimumkan) dan kendala-kendala yang ada ke dalam model matematik persamaan linier. Program linier sering digunakan dalam menyelesaikan problem alokasi sumber daya (Sitorus, 1997). Banyak persoalan yang penyelesaiannya menggunakan program linier, diantaranya persoalan transportasi, persoalan penugasan, program dinamis serta program bilangan bulat (Program Integer).

Program linier bilangan bulat (Integer Linier Programming) merupakan suatu model program linier yang khusus digunakan untuk menyesuaikan suatu problem dimana nilai variabel-variabel keputusan dalam penyelesaian optimal haruslah merupakan bilangan integer. Persyaratan bahwa nilai variabel keputusan harus bilangan integer mengingat jumlahnya tidak mungkin dalam bentuk pecahan, seperti rumah, pabrik, tugas, dan lain sebagainya ( Sitorus, 1997). 
Integer Linier Programming dapat diselesaikan dengan banyak cara, antara lain dengan menggunakan grafik, dengan metode eliminasi dan substitusi, dan sebagainya. Salah satu cara yang cukup efektif untuk menyelesaikan program integer adalah dengan mengaplikasikan algoritma Branch and Bound dibandingkan metode perhitungan nilai bulat lainnya dan telah menjadi kode Komputer standar untuk Integer Linier Programming (Aritonang, 2013).

\subsection{Rumusan Masalah}

Rumusan masalah dalam penulisan tugas akhir ini adalah bagaimana optimalisasi hasil produksi pada Pabrik Tempe ERI dengan menggunakan metode Branch and Bound?

\subsection{Tujuan}

Tujuan yang ingin dicapai dalam penulisan tugas akhir ini adalah memperoleh optimalisasi hasil produksi pada Pabrik Tempe ERI dengan menggunakan metode Branch and Bound.

\subsection{Manfaat Penelitian}

Adapun manfaat dari penelitiana ini, yaitu:

1. Sebagai salah satu penerapan ilmu yang didapat oleh peneliti selama masa perkuliahan.

2. Dari penelitian ini, diharapkan dapat dipergunakan sebagai masukan pabrik mengenai suatu model untuk mengoptimalkan hasil produksi.

\subsection{Batasan Penelitian}

Ruang lingkup dalam penulisan tugas akhir ini adalah sebagai berikut:

1. Data yang digunakan berasal dari Pabrik Tempe ERI yang berada di JI. Teratai No.04 Palu Selatan.

2. Harga kedelai diangggap tetap.

3. Tenaga kerja 4 orang dianggap tetap.

\section{METODE PENELITIAN}

Prosedur penelitian ini adalah sebagai berikut:

1. Melakukan studi literature dengan mengumpulkan materi dan buku-buku, artikel, dan jurnal yang didapat dari perpustakaan dan perpustakaan online.

2. Menganalisa masalah.

3. Memulai penelitian dengan mengambil data.

4. Menentukan variabel dari setiap masalah $\left(X_{j}\right)$. 
5. Memformulasikan masalah kedalam bentuk program linier .

6. Menyelesaikan model matematis dengan metode simpleks.

7. Solusi Integer dengan Metode Branch and Bound dengan menentukan batas serta cabang pada solusi simpleks non integer.

8. Menyelesaikan dengan menggunakan metode simpleks disetiap cabangnya menggunakan aplikasi TORA hingga mendapatkan solusi integer yang optimal.

9. Mendapatkan solusi yang integer dan optimal.

10. Menyimpulkan hasil penelitian.

11. Selesai.

\section{HASIL DAN PEMBAHASAN}

\subsection{Pengumpulan data}

Tabel 1 : Data Produksi Pabrik ERI

\begin{tabular}{|c|c|c|c|c|c|c|}
\hline \multirow[b]{2}{*}{ Bahan } & \multicolumn{4}{|c|}{ Satu Unit } & \multirow{2}{*}{$\begin{array}{c}\text { Persediaan } \\
\text { Maksimal/ } \\
\text { hari }\end{array}$} & \multirow[b]{2}{*}{ Satuan } \\
\hline & Tahu & $\begin{array}{l}\text { Tempe } \\
\text { Balak }\end{array}$ & Tempe Bulat & Tempe Kecil & & \\
\hline Kedelai & 6,81818 & 0,5 & 0,15 & 0,075 & 350 & $\mathrm{Kg}$ \\
\hline Kayu Bakar & 0,01704 & 0,00125 & 0,00037 & 0,00019 & 1 & $\mathrm{M}^{3}$ \\
\hline Bensin & 0,04545 & 0,00333 & 0,001 & 0,0005 & 3 & Liter \\
\hline Ragi Tempe & 0 & 0,01333 & 0,004 & 0,002 & 5 & gram \\
\hline Cuka & 0,06818 & 0 & 0 & 0 & 2 & Liter \\
\hline Tenaga Kerja & 0,06818 & 0,005 & 0,0015 & 0,00075 & 14 & Jam/orang \\
\hline Harga (Rp/Unit) & 95.000 & 8.000 & 1.500 & 900 & & $\mathrm{Rp}$ \\
\hline
\end{tabular}

Sumber : Pabrik Tempe ERI

\subsection{Penentuan Variabel (peubah) Keputusan}

Adapun variabel -variabel dalam model ini adalah sebagai berikut :

$x_{1}=$ jumlah tahu yang diproduksi/hari

$x_{2}=$ jumlah tempe balak yang diproduksi/hari

$x_{3}=$ jumlah tempe bulat yang diproduksi/hari

$x_{4}=$ jumlah tempe kecil yang diproduksi/hari

\subsection{Membangun Model Matematika}

Fungsi tujuan :

Maksimumkan $z=95.000 x_{1}+8.000 x_{2}+1.500 x_{3}+900 x_{4}$

Batasan-batasan:

$6,81818 x_{1}+0,5 x_{2}+0,15 x_{3}+0,075 x_{4} \leq 350$ 


$$
\begin{aligned}
& 0,01704 x_{1}+0,00125 x_{2}+0,00037 x_{3}+0,00019 x_{4} \leq 1 \\
& 0,04545 x_{1}+0,00333 x_{2}+0,001 x_{3}+0,0005 x_{4} \leq 3 \\
& 0,01333 x_{2}+0,004 x_{3}+0,002 x_{4} \leq 5 \\
& 0,06818 x_{1} \leq 2 \\
& 0,06818 x_{1}+0,005 x_{2}+0,0015 x_{3}+0,00075 x_{4} \leq 14
\end{aligned}
$$

\subsection{Solusi Integer dengan Metode Branch and Bound}

Persoalan Program Integer (IP) adalah persoalan pemograman (programming) di mana pemecahan optimalnya harus menghasilkan bilangan integer (bulat) jadi bukan pecahan. Dengan perkataan lain dari antara berbagai bilangan integer, harus dicari nilai-nilai variabel yang fisibel (layak) dan membuat fungsi tujuan (Objective function) maksimum (Supranto, 1980).

Menurut Mulyono (2004), program integer dibutuhkan ketika keputusan harus dalam bentuk bilangan integer. Model matematis dari program integer sebenarnya sama dengan model program linier, dengan tambahan batasan bahwa variabel keputusannya harus bilangan integer. Program integer adalah suatu program linier dengan tambahan persyaratan bahwa semua atau beberapa variabel bernilai bulat non negative.

Metode Branch and Bound (cabang dan batas) adalah salah satu metode untuk menghasilkan penyelesaian optimal pemograman linier yang menghasilkan variabel-variabel keputusan bilangan bulat. Sesuai dengan namanya, metode ini membatasi penyelesaian optimum yang akan menghasilkan bilangan pecahan dengan cara membuat cabang atas dan bawah bagi masing- masing variabel keputusan yang bernilai pecahan agar bernilai bulat sehingga setiap pembatasan akan menghasilkan cabang baru (Siswanto, 2007).

\subsubsection{Menentukan Batas Atas Awal dan Batas Bawah (Branch)}

Solusi optimal dari metode simpleks didapatkan $x_{1}=23,82646, \quad x_{2}=$ 375,09377, $x_{3}=0$, dan $x_{4}=0$ dijadikan batas atas awal yaitu: $z=5.264 .263,86$. Sedangkan hasil pembulatan ke bawah sebagai batas bawah $x_{1}=23, x_{2}=375, x_{3}=$ 0 , dan $x_{4}=0$, berdasarkan persamaan (1) batas bawah dapat ditentukan sebagai berikut:

$$
\begin{aligned}
& z=95.000 x_{1}+8.000 x_{2}+1.500 x_{3}+900 x_{4} \\
& z=95.000(23)+8.000(375) \\
& z=5.185 .000
\end{aligned}
$$




\subsubsection{Pencabangan (Bound)}

Karena $x_{1}=23,82646$ memiliki nilai pecah terbesar, dua kendala baru diciptakan sehingga diperoleh dua masalah baru melalui dua kendala mutually exclusive yaitu $x_{1} \leq 23$ dan $x_{1} \geq 24$. Masukan masing-masing nilai kendala baru dari hasil pencabangan pada nilai kendala dan fungsi tujuan asli, pada solusi cabang yang tidak layak langsung bisa dibuang atau dihentikan. Penambahan dua kendala baru dapat diuraikan sebagai berikut:

- $\quad$ Untuk $x_{1} \leq 23$

Fungsi tujuan :

Maksimumkan $z=95.000 x_{1}+8.000 x_{2}+1.500 x_{3}+900 x_{4}$

Batasan-batasan :

$6,81818 x_{1}+0,5 x_{2}+0,15 x_{3}+0,075 x_{4} \leq 350$

$0,01704 x_{1}+0,00125 x_{2}+0,00037 x_{3}+0,00019 x_{4} \leq 1$

$0,04545 x_{1}+0,00333 x_{2}+0,001 x_{3}+0,0005 x_{4} \leq 3$

$0,01333 x_{2}+0,004 x_{3}+0,002 x_{4} \leq 5$

$0,06818 x_{1} \leq 2$

$0,06818 x_{1}+0,005 x_{2}+0,0015 x_{3}+0,00075 x_{4} \leq 14$

$x_{1} \leq 23$

Solusi Simpleks:

$x_{1}=23,83, x_{2}=375,09, x_{3}=0, x_{4}=0$ dan $z=5.264 .263,86$

- $\quad$ Untuk $x_{1} \geq 24$.

Fungsi tujuan :

Maksimumkan $z=95.000 x_{1}+8.000 x_{2}+1.500 x_{3}+900 x_{4}$

Batasan-batasan :

$6,81818 x_{1}+0,5 x_{2}+0,15 x_{3}+0,075 x_{4} \leq 350$

$0,01704 x_{1}+0,00125 x_{2}+0,00037 x_{3}+0,00019 x_{4} \leq 1$

$0,04545 x_{1}+0,00333 x_{2}+0,001 x_{3}+0,0005 x_{4} \leq 3$

$0,01333 x_{2}+0,004 x_{3}+0,002 x_{4} \leq 5$

$0,06818 x_{1} \leq 2$

$0,06818 x_{1}+0,005 x_{2}+0,0015 x_{3}+0,00075 x_{4} \leq 14$

$x_{1} \geq 24$.

Solusi Simpleks:

$x_{1}=24, x_{2}=372,73, x_{3}=0, x_{4}=0$ dan $z=5.261 .818,88$

Proses pencabangan ini dilakukan terus hingga mendapatkan solusi bulat layak dimana Batas atas = Batas Bawah $=Z=5.259 .600$. Dapat di lihat pada Prosedur Branch and Bound dibawah ini: 
3.4.3. Prosedur Branch and Bound

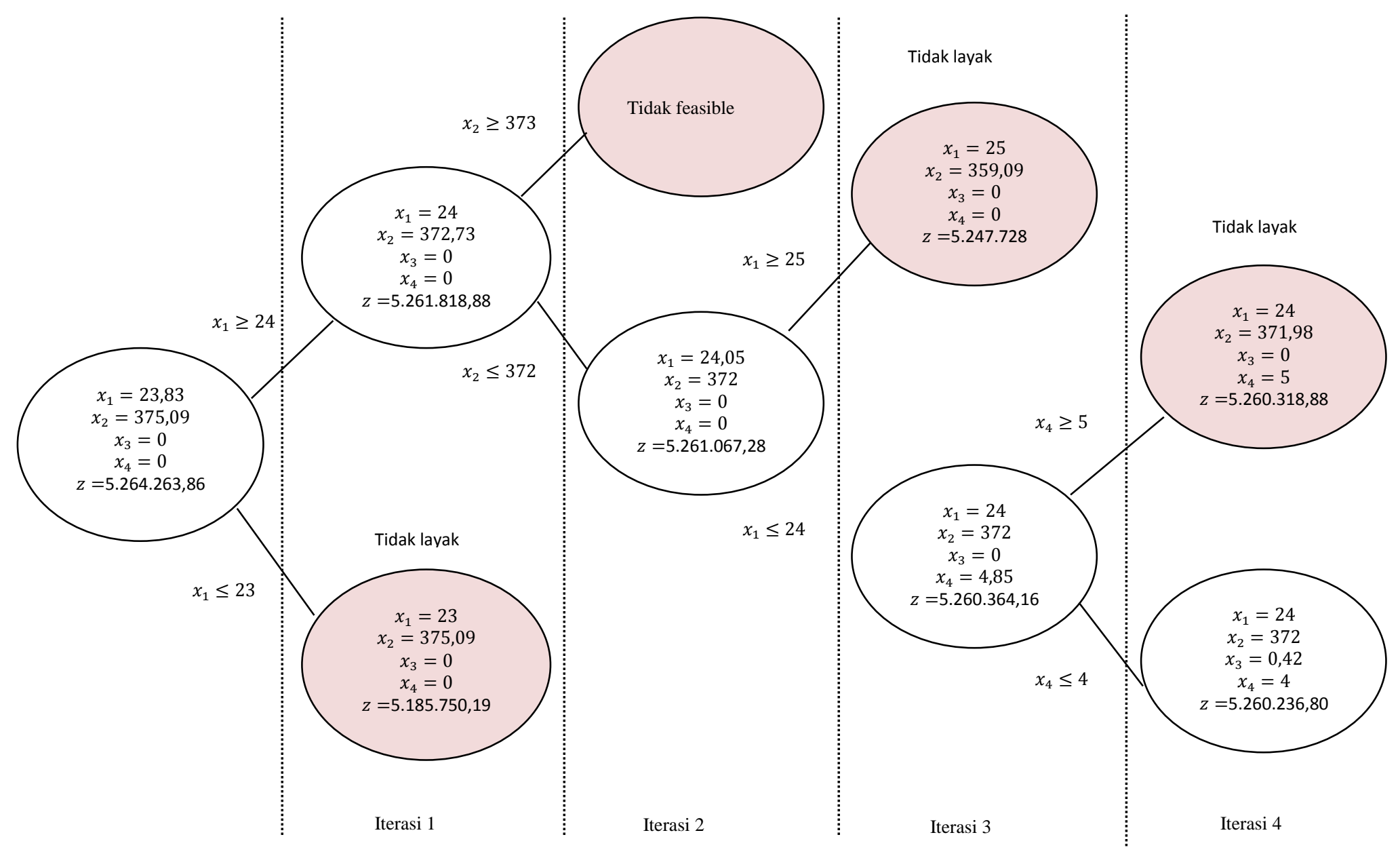




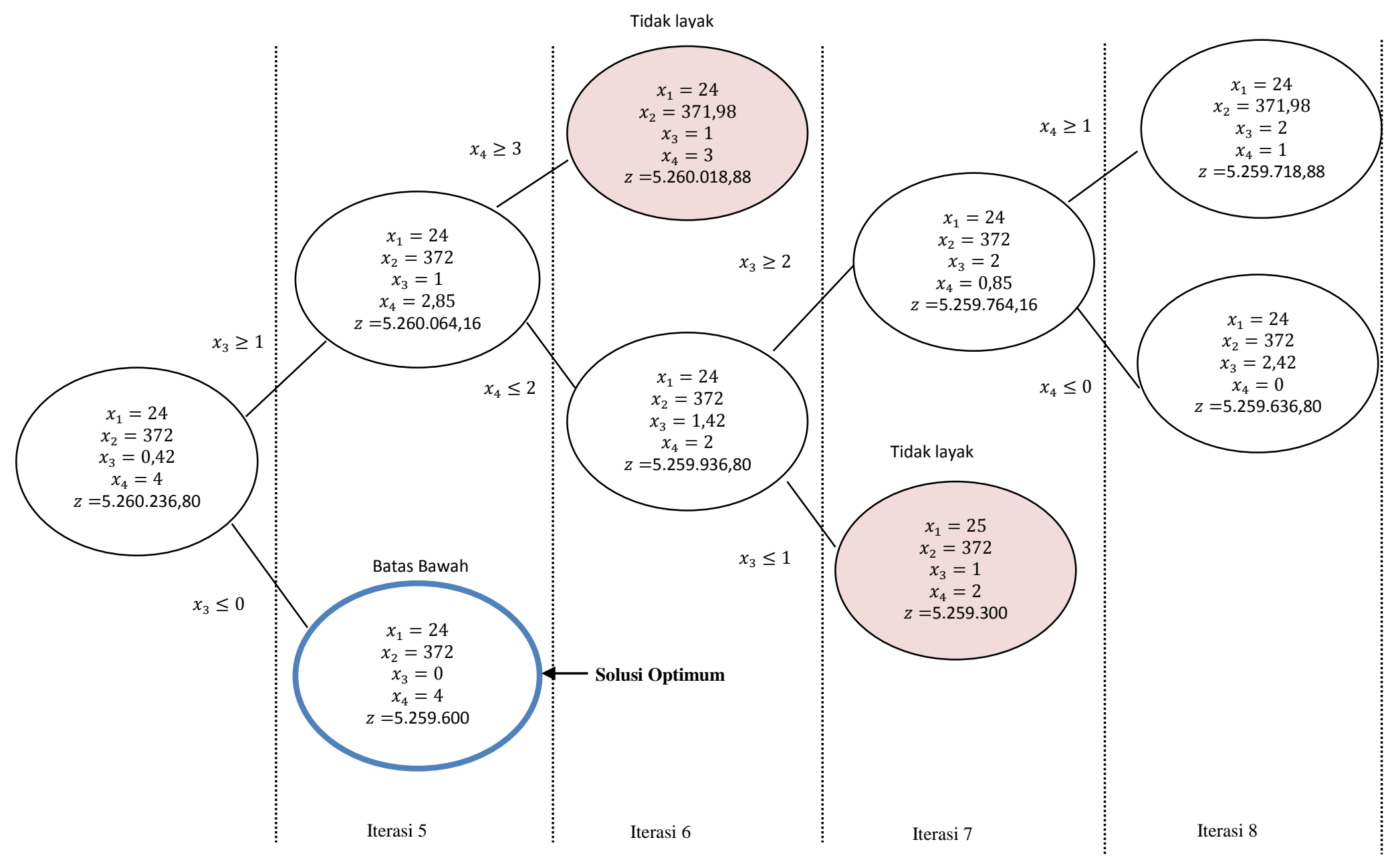




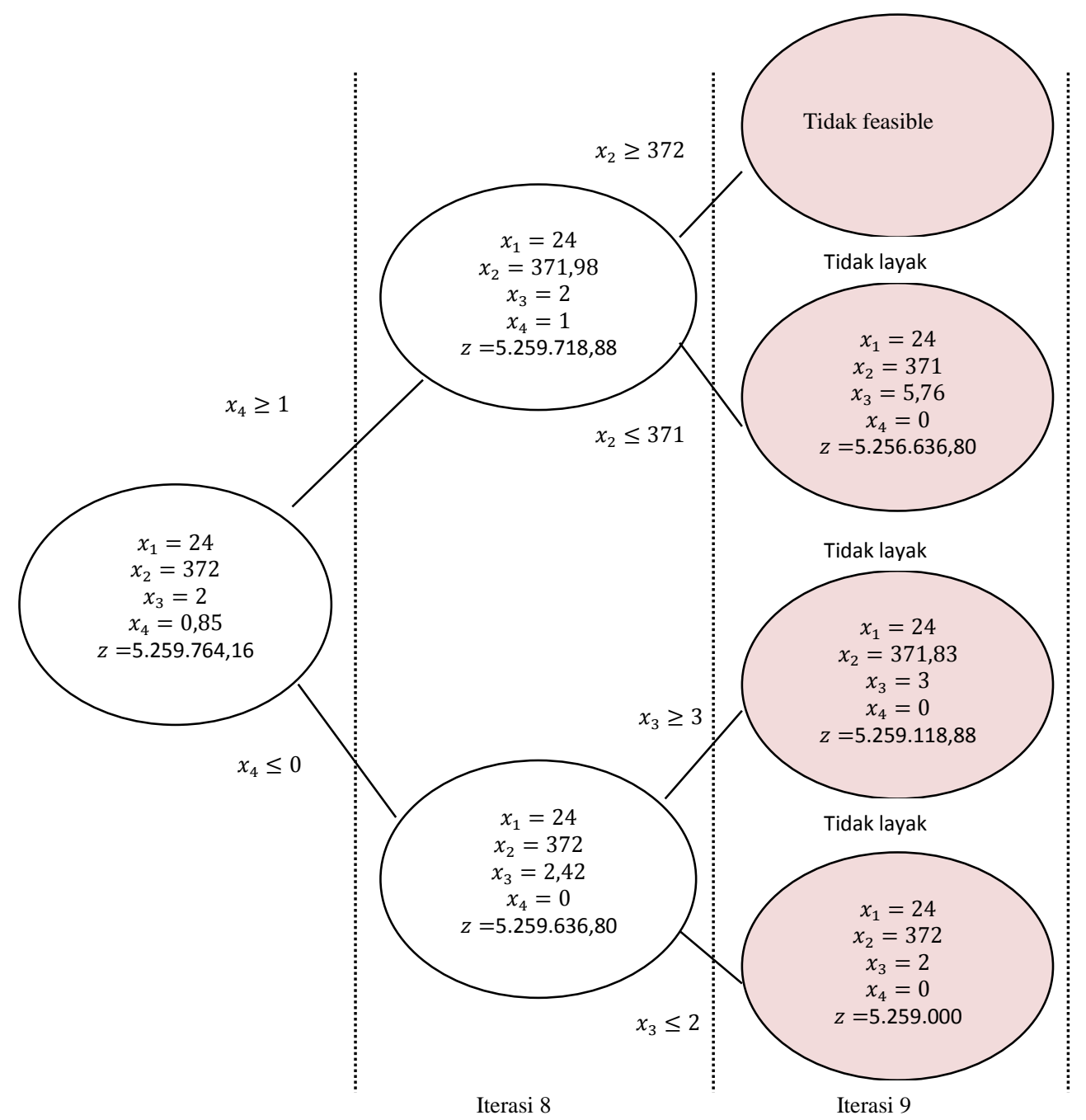




\subsection{Pembahasan}

Optimalisasi dilakukan untuk mendapatkan hasil produksi dan keuntungan yang optimal dengan keterbatasan sumber daya yang ada. Berdasarkan hasil penyelesaian menggunakan Metode Branch And Bound didapatkan penyelesaian optimal bulatnya adalah bahwa jumlah tahu $(50 \mathrm{~cm} \times 50 \mathrm{~cm})$ yang bisa diproduksi setiap harinya adalah sebanyak 24 unit, jumlah tempe balak $(20 \mathrm{~cm} \times 40 \mathrm{~cm})$ yang bisa diproduksi sebanyak 372 unit, dan jumlah tempe kecil $(9 \mathrm{~cm} \times 14 \mathrm{~cm})$ sebanyak 4 unit, sedangkan untuk tempe bulat $(3 \mathrm{~cm} \times 50 \mathrm{~cm})$ pabrik tidak perlu memproduksinya.

Dengan memasukan nilai $x_{1}, x_{2}, x_{3}$ dan $x_{4}$ ke dalam persamaan (1) maka penghasilan pabrik dalam sehari adalah sebanyak:

$z=95.000 x_{1}+8.000 x_{2}+1.500 x_{3}+900 x_{4}=5.259 .600$

Jadi, penghasilan optimal yang dapat diperoleh pabrik ERI setiap hari adalah sebesar Rp. 5.259.600.

Dengan penggunaan $350 \mathrm{~kg}$ kedelai, $1 \mathrm{~m}^{3}$ kayu bakar, 3 liter bensin, 5 gram ragi tempe, 2 liter cuka dan $14 \mathrm{jam} /$ orang tenaga kerja, pabrik dapat memproduksi tahu $(50 \mathrm{~cm} \mathrm{x}$ $50 \mathrm{~cm})$ sebanyak 24 unit, tempe balak $(20 \mathrm{~cm} \times 40 \mathrm{~cm})$ sebanyak 372 unit, dan tempe kecil $(9 \mathrm{~cm} \times 14 \mathrm{~cm})$ sebanyak 4 unit dengan penghasilan diperoleh setiap hari adalah sebanyak Rp. 5.259 .600 .

\section{KESIMPULAN}

Berdasarkan hasil penelitian atas masalah yang terjadi pada pabrik tempe ERI dengan penggunaan $350 \mathrm{~kg}$ kedelai, $1 \mathrm{~m}^{3}$ kayu bakar, 3 liter Bensin, 5 gram ragi tempe, 2 liter cuka dan $14 \mathrm{jam} /$ rang tenaga kerja. Dapat ditarik kesimpulan bahwa:

1. Solusi fisibel produksi pada pabrik tempe ERI menggunakan metode simpleks adalah $x_{1}=$ 3,82646, $x_{2}=375,09377, x_{3}=0$, dan $x_{4}=0$, dengan $\mathrm{z}=5.264 .263,86$. Solusi integer yang optimum menggunakan metode Branch and Bound menghasilkan $x_{1}=24, x_{2}=372, x_{3}=0$, $x_{4}=4$ dengan $z=5.259 .600$.

2. Hasil produksi optimal tahu $(50 \mathrm{~cm} \times 50 \mathrm{~cm})$ sebanyak 24 unit, tempe balak $(20 \mathrm{~cm} \times 40 \mathrm{~cm})$ sebanyak 372 unit, dan tempe kecil $(9 \mathrm{~cm} \times 14 \mathrm{~cm})$ sebanyak 4 unit dengan penghasilan diperoleh setiap hari adalah sebanyak Rp. 5.259.600 lebih maksimal dibandingkan dengan sebelum menggunakan perhitungan metode Branch and Bound yaitu penghasilan yang diperoleh setiap hari adalah hanya Rp. 4.130.000. 


\section{DAFTAR PUSTAKA}

[1]. Aritonang, D,R,S. 2013. Analisis Metode Branch and Bound Dalam Mengoptimalkan Produksi Roti. FMIPA Universitas Sumatera Utara. Medan.

[2]. Mulyono,S. 1991. Operation Research. Lembaga Penerbit Fakultas Ekonomi Ul. Jakarta.

[3]. Siswanto. 2007. Operation Research. Jilid I. Erlangga. Jakarta.

[4]. Sitorus, P. 1997. Program Linier. Universitas Trisakti. Jakarta.

[5]. Supranto, J. 1980. Linier Programming. Fakultas Ekonorni Universitas Indonesia. Jakarta. 